\title{
O DIREITO ENQUANTO FIO CONDUTOR PARA A APLICAÇÃO DA JUSTIÇA: UMA ANÁLISE DO LIVRO II DAS ORDENANZAS REALES DE CASTILLA
}

\section{Fernanda de Paula Ferreira Moi*}

\section{RESUMO ${ }^{1}$ :}

Muito já se discorreu sobre o reinado de Fernando e Isabel e várias questões podem ser debatidas, destacando-se os seus aspectos jurídicos. O artigo analisa os conceitos de Direito e Justiça durante o reinado dos Reis Católicos e o Livro II das Ordenanzas Reales de Castilla. Dentre os questionamentos que nos norteiam, destacamos: como um ordenamento jurídico fundado no conceito de Justiça fortalece a estruturação do próprio exercício do Poder? Para o desenvolvimento do presente artigo serão utilizados os métodos histórico e hermenêutico; a metodologia usada será a revisão bibliográfica e estudo das fontes históricas.

PALAVRAS-CHAVE: Ordenanzas Reales de Castilla. Reis Católicos. Direito. Justiça.

\section{THE LAW AS A LEADER FOR THE APPLICATION OF JUSTICE: AN ANALYSIS OF BOOK II OF THE ORDANZAS REALES DE CASTILLA}

\begin{abstract}
:
Much has been said about the reign of Fernando and Isabel and several issues can be debated, highlighting their legal aspects. The article analyzes concepts of Law and Justice during the reign of the Catholic Kings and Book II of the Ordanzas Reales de Castilla. Among the questions that guide us, we highlight: how does a legal system based on the concept of Justice strengthen the structuring of the exercise of Power itself? For the development of this article, the historical and hermeneutic methods will be used; the methodology used will be the bibliographic review and study of historical sources.
\end{abstract}

KEYWORDS: Ordenanzas Reales de Castilla, Catholic Kings, Law, Justice.

\section{INTRODUÇÃO:}

O presente artigo encontra-se delimitado, geograficamente, no reino ibérico de Castela e, cronologicamente, durante o período compreendido entre os anos de 1474 a 1504, ou seja, da ascensão de Isabel de Castela ao trono até sua morte.

Durante o reinado de Fernando de Aragão e Isabel de Castela, os chamados Reis Católicos, muitos projetos foram por eles levados a cabo para a consolidação da Monarquia

\footnotetext{
* Doutora em História pela Universidade Federal de Goiás (UFG/FH). Mestre em Direito pela Universidade de Ribeirão Preto (UNAERP). Professora adjunta na Universidade Federal de Goiás (UFG/UAECSA-Regional Goiás); Professora Adjunta na Pontifícia Universidade Católica de Goiás (PUC-Goiás). Advogada. Pesquisadora. Atualmente em estágio Pós-doutoral no Programa de Pós Graduação em Direito e Políticas Públicas da Universidade Federal de Goiás (PPGDPP/UFG). E-mail: nandamoi@icloud.com

${ }^{1} \mathrm{O}$ presente artigo é fruto das pesquisas que se iniciaram durante nosso processo de doutoramento e que se desmembraram em projetos de pesquisa em programas de Iniciação Científica na PUC-Goiás e na UFG.
} 
espanhola. Dentre tantos projetos destacamos, tendo em vista o objeto do presente artigo, a intensa produção legislativa do período, sobretudo as Ordenanzas Reales de Castilla.

Dada a magnitude do projeto por eles lançados, vários autores, das mais diversas épocas, passaram a identificá-los como forjadores do Estado Moderno espanhol. Em tais textos, objeto da discussão tanto de historiadores quanto de literatos, referido período histórico é visto como extremamente rico e produtivo, onde Fernando e Isabel são retratados como sendo responsáveis pela superação do caos e instalação da ordem, a partir da construção de uma política pautada no Direito e na Justiça. Todavia, de acordo com o que observa Vidotte (2006: 10), a partir da segunda metade do século XX, historiadores passam a rever esta visão romântica até então adotada e concluem que, em verdade, o grande mérito dos Reis Católicos deve-se ao fato de que eles se utilizaram e incrementaram instrumentos já existentes, criando outros e promovendo novas ações integradoras, canalizando os sentimentos e as forças presentes nos diferentes reinos peninsulares para um objetivo maior, qual seja: a consolidação da Monarquia.

Assim, o projeto centralizador dos Reis Católicos pautou-se nos conceitos de Direito e de Justiça, conceitos fundamentais para a centralização e consolidação do Poder, sendo que a análise, ainda que sucinta, dos conceitos então vigentes de Direito e Justiça se mostra essencial para que possamos atingir o objetivo perseguido por este artigo, qual seja: o de se demonstrar a importância do Direito para a consecução da Justiça.

No período histórico no qual se situa o objeto do presente artigo, o conceito de Justiça, de justo e injusto, era fortemente influenciado pela Igreja Católica. Neste sentido, filósofos da época entendiam que o conceito de Justiça, bem como o de norma justa ou injusta, se referia, diretamente, aos Dez Mandamentos e à concepção de Direito Natural então vigente. Havia a concepção de que as leis positivadas encontravam seu fundamento de legitimação e fundamentação nas próprias leis naturais, as quais, por sua vez, encontravam sua fundamentação e legitimação nas leis divinas. Assim, o conceito de Justiça então vigente era compreendido como disposição constante de dar a cada um o que lhe era devido.

Faz-se oportuno ressaltar que a Monarquia (aquela que se opõe à tirania) encontra seu fundamento nos conceitos de Direito e de Justiça. Neste sentido, as atitudes do monarca devem ser limitadas pelo próprio ordenamento jurídico, sendo que este, no momento de sua elaboração, reflete os posicionamentos ideológicos então vigentes. No período ora analisado, lembremo-nos que a fundamentação e legitimação das normas jurídicas baseavam-se na 
concepção tomista de Direito Natural, ou seja, aquele advindo das normas divinas. Também importante ressaltar que, no que se refere à legitimação da monarquia, tão importante quando o Direito e Justiça, a História e Tradição desempenham papel fundamental.

A partir de tais reflexões, podemos pensar o porquê de o reinado dos Reis Católicos ter sido visto como um momento particularmente justo da História espanhola, afinal, todo o projeto restaurador dos monarcas se baseava no conceito de Justiça então vigente. E é a partir da compreensão do conceito de Justiça que poderemos trabalhar o próprio conceito de Direito, pois ambos sempre estiveram intimamente ligados.

Deste modo, para que trabalhemos tais conceitos, sobretudo a questão da caracterização de tal período como extremamente justo, analisaremos a estrutura jurídico vigente à época. Para tanto, partiremos do estudo das Ordenanzas Reales de Castilla, em específico, seu Livro II.

As escolha do presente tema se justifica pois os conceitos de multidisciplinaridade e interdisciplinaridade permeiam, na atualidade, pesquisas nas áreas das ciências sociais e ciências sociais aplicadas. A partir dos recortes geográfico e cronológico propostos, percebese que um corpo jurídico de peso, baseado no conceito de Justiça, é de suma importância para a manutenção e fortalecimento das formas puras de governo, a partir de uma visão aristotélica. Ademais, a historiografia, embasada em fontes historiográficas e resgate da memória, tem como finalidade não apenas o registro escrito da História, mas também o estudo da História propriamente dita.

Para o desenvolvimento do presente artigo forma utilizados os métodos histórico e hermenêutico e a metodologia se baseou na revisão bibliográfica e análise das fontes históricas.

\section{DO REINADO DOS REIS CATÓliCOS E SEU PROJETO CENTRALIZADOR ${ }^{2}$}

\footnotetext{
${ }^{2}$ Por questões metodológicas não adentraremos à crise que perpassou o reinado de Enrique IV, tampouco à ascensão de Isabel ao trono. Para nos atermos ao objeto de nosso artigo, daremos início às nossas discussões a partir dos planos matrimoniais e como estes são essenciais para que o projeto integrador se materialize.
} 
O casamento de Isabel, de suma importância para se levar a cabo o projeto integrador por eles arquitetado, começou a ser discutido ainda durante a crise que envolveu nobreza e realeza.

Antes de seu casamento com Fernando, outros planos haviam sido traçados pois o casamento da herdeira ao trono se apresentava como assunto de Estado e colocava-se como de extrema importância para a coroa de Castela e para a monarquia hispânica. Dada a importância do matrimônio, três pretendentes foram apresentados: Carlos, duque de Guiana e irmão do rei francês Luís XI; Afonso, rei de Portugal e; Fernando, príncipe de Aragão e rei de Sicília.

Em vista da crise enfrentada em Castela, em vista do dualismo entre partidários de Juana e os partidários de Isabel, em vista das opções de matrimônio apresentadas, os aliados de Enrique IV e partidários de Juana defendiam o casamento com Afonso V; os partidários de Isabel, por sua vez, defendiam seu casamento com Fernando.

Isabel, em uma decisão muito acertada do ponto de vista político, escolheu Fernando como seu cônjuge. De acordo com Pulgar,

\begin{abstract}
No solamente los grandes, mas los perlados, los clérigos, los caballeos, los fidalgos, los ciudadanos, y generalmente todos los tres estados y comunes del reuno mostraban placerles del matrimonio con ele principe de Aragón, por las utilidades y conveniencias que en él mas que en otros parecian, y les pesaria si en otra parte lo concluyese (PULGAR, 1943, p. 14).
\end{abstract}

Contrariando a vontade de seu irmão, Isabel se casou com Fernando no ano de 1469. Esse evento foi suficiente para que Enrique IV se valesse do matrimônio realizado a sua revelia para deserdar Isabel e declara Juana como legítima herdeira do trono. Posteriormente, em 1473, Enrique e Isabel se reconciliaram e, no ano seguinte, o rei, solenemente recebeu Fernando. Neste mesmo ano, Enrique IV partiu para Madri, deixando a fortaleza de Segóvia sob o comando de Isabel. Aos 11 de dezembro de 1474, Enrique IV morreu sem deixar testamento.

Enrique IV, ao deixar a fortaleza de Segóvia, principal fortaleza régia e símbolo do poder real castelhano, sob os cuidados de Isabel fortaleceu os argumentos defendidos por seus partidários de que ela era a verdadeira herdeira do trono. Todavia, em nenhum momento os atos jurídicos de Valdelozoya, que declaravam Juana como legítima sucessora, foram revogados, e isso gerou acaloradas discussões. 
O fato é que, após a morte do irmão, Isabel foi proclamada rainha; todavia, sem se seguir a tradição dos Trastâmaras, Isabel levou a cabo as exéquias pelo rei morto antes de realizar as cerimônias de ascensão ao trono. Não podemos afirmar que tal atitude se tratou de estratégia política, mas o fato é que, diante de sua postura, Isabel ganhou prestígio.

\begin{abstract}
[...] nos hallamos ante un procedimiento cerimonial diferenciado del observado con motivo de otras muertes regias antes estudiadas. En cuanto se conoce la muerte del rey, no se açude de inmediato a ceremonializar, por resumido que sea el procedimiento que se utilice, el acceso al trono del sucesor, sino que se prefiere llevar a cabo las esquis por el rey difunto que, además, se hacen con una notable pompa y, sobre todo, con una destacada y buscada dimensión pública. Parece indudable que tal forma de proceder no careció de justificación política. Ante las dificiles relaciones entre Isabel y Enrique IV y ante las disputas previas por la sucesión, se trato de recurrir a la imagem de continuidad dinástica y respeto publico, expresado por via ceremonial, hacia el monarca fallecido, en cuanto que eran estas actitudes las que mejor contribuían a legitimar en aquel momento los propios derechos de Isabel ao trono. Así, por tanto, estas exéquias reales, celebradas en Segovia, puden considerarse como resultado de una buscada funcionalidad propagandística, a través de la cual, se aseguraba una mayor eficácia legitimadora para los actos de entronización que habá de seguirlas, razón por la cual se romperia la tradicional sucesión de celebraciones características de situaciones semejantes (NIETO SORIA, 1993, p. 107).
\end{abstract}

Após as exéquias se deu a entronização de Isabel, na cidade de Segóvia. Fernando não esteve presente durante a cerimônia, chegando apenas dois dias após, o que gerou um mal-estar entre o casal. De acordo com Pulgar,

Como la Princesa que estaba en la cibdad de Segovia sopo la muerte del rey Don Enrique su hermano, luego se intituló Reyna de Castilla é de Leon é fizo las obsequias muy solennes por el ánima del Rey. Otrosí allí en Segovia se fizo por los de la cibdad un cadalso, do viniéron todos los Caballeros é Regiedores é la Clerecía de la cibdad, é alzaron en él los pendones Reales, diciendo: Castilla, Castilla por el Rey Don Fernando e la Reyna Dona Isabel su muger proprietaria destos Reynos: é besaronle todos las manos, conociéndola por Reyna é Señora dellos, é ficiéron la solenidad é juramento de fidelidad, que por las leyes destos Reynos es instruido que se debe facer en tal caso á sus verdaderos Reyes (PULGAR, 1943, p. 32).

Os partidários de Juana, descontentes com a entronização de Isabel, buscaram apoio junto aos portugueses na tentativa de proclamarem Juana como legítima sucessora ao trono de Castela. Neste sentido, iniciou-se a Guerra de Sucessão que durou por quatro anos e passou a ter contornos internacionais. Ao final da guerra, foram assinados quatro tratados (os Tratados de Alcaçobas), os quais versavam sobre a expansão marítima, a anistia aos nobres castelhanos desterrados, a liberdade aos prisioneiros de guerra e a devolução das terras conquistadas durante a Guerra, bem como sobre a promessa de casamento da filha primogênita de Fernando 
e Isabel com o filho do príncipe Juan de Portugal. Por fim, o último dos tratados disciplinava acerca do futuro de Juana.

Para Juana foram apresentadas duas opções: casar-se com o herdeiro dos Reis Católicos, que a época tinha apenas um ano de idade; ou, viver reclusa em um convento das Clarissas, tendo sido esta a opção escolhida por Juana.

Para maior legitimidade de seu poder, Fernando e Isabel obtiveram Bula Papal proibindo a saída de qualquer monja Clarissa do convento. Essa atitude por parte de Fernando e Isabel nos leva a crer que eles tinham grandes preocupações com Juana, por entenderem que ela representaria um perigo de abalo ao reinado. Todavia, o que se presencia é que, ao final da Guerra de Sucessão, Fernando e Isabel se fortaleceram e puderam dar seguimento ao seu projeto centralizador.

Em vista do contexto no qual Isabel assume o trono, em vista das alterações por ela e Fernando realizadas, eles passam a ser vistos como restauradores da ordem pública e jurídica.

Interessante observar que havia se construído, ao longo da Idade Média, um ideal de Hispânia, ideal este que se perdeu, em 711, quando da conquista do território por parte dos muçulmanos. Todavia, a restauração desse antigo ideal, agora chamado de ideal neogótico (PIAL apud FERNANDEZ: 1962, p. 5-7) passa a ser um sonho almejado por Fernando e Isabel. Em verdade, esse sonho se converteu em um verdadeiro projeto de governo.

Fernando e Isabel, ao ascenderem ao trono, deram início a esse projeto centralizador, que na verdade ia muito além do ideal de solidariedade entre os reinos pois projetava-se em uma ideia de unidade. Neste sentido, caminharam para a centralização do poder por meio de bases jurídicas que foram construídas durante esse novo reinado.

Para fins de seu projeto centralizador, ficava determinado que os Reis exerceriam suas funções por meio da restauração da Justiça sendo que, para fins propagandísticos, passava-se uma imagem de reis extremamente justos. Neste sentido, Pedro de Anglería nos demonstra que

El Rey y la Reyna son consortes que gobiernan las das Españas con perfecta justitcia ... puedo, gracias a estos dos meses de experiencia asegurar que si alguna vez se puso en discusión la possibilidad de que entre los mortales dos cuerpos estuvieron de un solo espíritu, son estos efectivamente, pues están regidos por un solo pensamiento y un solo alma $(1955, \mathrm{I})$. 
Fernando, desta feita, tornou-se reconhecido como um monarca que aplicava a Justiça e respeitava as leis vigentes, sendo considerado exemplo de Príncipe a ser seguido. Para Maquiavel,

\begin{abstract}
Nada faz estimar tanto um príncipe como as grandes empresas e o dar de si raros exemplos. Temos, nos nossos tempos, Fernando de Aragão, atual rei de Espanha. A este pode-se chamar, quase, príncipe novo, porque de um rei fraco tornou-se, por fama e por glória, o primeiro rei dos cristãos; e, se considerardes suas ações, as achareis todas grandiosas e algumas mesmo extraordinárias.

[...] Além disto, para poder encetar maiores empreendimentos, servindo-se sempre da religião, dedicou-se a uma piedosa crueldade expulsando e livrando seu reino dos marranos, ação de que não pode haver exemplo mais miserável nem mais raro.

[...] Muito apraz a um príncipe dar de si exemplos raros na forma de comportar-se com os súditos [...] Acima de tudo, um príncipe deve empenhar-se em dar de si, com cada ação, conceito de grande homem e de inteligência extraordinária.

[...] Deve, ainda, um príncipe mostrar-se amante das virtudes, dando oportunidade aos homens virtuosos e honrando os melhores numa arte.

(2011, p. 129-130).
\end{abstract}

Cumpre observar que, para alguns autores, o objetivo principal de Fernando e Isabel era a recuperação dos contornos da antiga Hispânia. Para outros, por sua vez, seu principal objetivo era o fortalecimento do poder real face à nobreza e consequente centralização do poder. Nós, particularmente, defendemos essa segunda linha de pensamento.

\title{
2. DOS CONCEITOS DE DIREITO E JUSTIÇA DURANTE O REINADO DOS REIS CATÓLICOS
}

A instituição da Justiça e do Direito é vista como ponto de partida para a própria historiografia, em um despertamento de reflexões sobre a criação e fundamentação de uma sociedade, mesmo nas mais primitivas. Tais instituições servem para assegurar a ordem com seus princípios e, consequentemente, a sobrevivência daqueles que vivem num dado grupo. A partir dessa observação, trataremos os conceitos de Direito e de Justiça durante o reinado dos Reis Católicos, sua fundamentação teórico-filosófica, bem como a adoção de determinados conceitos de Direito e de Justiça que serviram para a elaboração e a utilização do ordenamento jurídico vigente na época. Tais levantamentos apresentam os fundamentos de um projeto centralizador intentados pelos Reis Católicos.

Os teóricos que abordam os intentos de Fernando e Isabel observam como se deu a (re)estruturação do sistema jurídico da época, bem como a aplicação da Justiça aos casos 
necessários, sendo, neste contexto, o conceito de Justiça concebido a partir dos ideais aristotélico e tomista de Direito e Justiça ${ }^{3}$.

Recordemo-nos que o período dos Trastâmaras foi período conturbado, especialmente durante os reinados de Juan II e Henrique IV. Em vista disto, os teóricos de Fernando e Isabel se questionavam sobre o que era Justiça e como ela deveria ser aplicada. Dentre tais teóricos, destacamos Rodrigo de Arévalo ${ }^{4}$ e Diego de Valera ${ }^{5}$. Arévalo, na Suma de la política, demonstra a importância da Justiça para a manutenção dos reinos.

Sant Agustín, en el segundo de la Ciudad de Dios, rezando la sentencia de un sábio, dize que nenguna republica ni comunidad se puede sostener sin justiçia, y no ay cosa más enemiga a cualquier cibdad o reino que la injustiçia; ca, apartada la justiçia de los reinos, pierden sus nombres y son llamados ladronicios y no reinos; $y$ de tanto rigor es la justiçia, que sin Ella los omes no podríam vivir (ARÉVALO, II, X, p. 299).

Arévalo, resgatando os ensinamentos agostinianos, entendia que Justiça era dar a cada um o que lhe é devido com intuito de se atingir a paz. Neste sentido, "Y assí que de tanta virtud es la justicia que aun es necessaria a los robadores e tiranos, pues esta justicia política de que al presente fablamos deve ser tal como la escrive San Bernaldo: Justicia es dar a cada uno lo que es suyo" (ARÉVALO, Sum. Pol., II, XI, p. 299).

Diego de Valera, por sua vez, utilizou-se dos conceitos aristotélico e tomista para a formulação do que entende por Justiça. Para ele, em sua Exortación de la pas:

Aqui es de notar que la justicia, segunt el Filósofo, es un ábito o condición por el
qual somos obradores de justas caussas; ca de la justicia es causada en el onbre
una inclinación a las obras justas por las quales el obbre se faze desseador e
amador de aquéllas. E así por la gran continuación de obras justas el onbre es
fecho justo, ni se deve ni puede el onbre dezir justo porque obre algunas cossas de
justicia, mas dezir se justo porque obre algumas cossas de justicia, mas dezir se a
justo quando tiene en la voluntad causada una firme e constante condición a querer
las cossas justas e buenas. Así está la justicia en la voluntad como en su próprio
subieto de donde las justas obras proceden. Pues el ábito o condición de la voluntad

\footnotetext{
${ }^{3}$ Os conceitos de Direito e Justiça para Aristóteles e Aquino não serão abordados no presente artigo por questões metodológicas. Neste sentido, analisaremos somente os conceitos de Direito e Justiça para os teóricos de Fernando e Isabel.

${ }^{4}$ Rodrigo de Arévalo (1404-1470) foi um dos pensadores mais influentes nos âmbitos da cultura, bem como da história política e eclesiástica da Coroa de Castela do sec. XV, sobretudo, durante o reinado de Enrique IV, dedicando seus estudos às teorias clássicas e medievais sobre sociedade, poder e Estado, tendo estudado Direito na Universidade de Salamanca. Merece destaque, para fins da presente pesquisa, sua obra Suma de la Política (1455), onde segue os ensinamentos de Aristóteles em sua obra $A$ política. Disponível em: $<$ https://espania.revues.org/20944?lang=es>. Acesso em: jul. 2016.

${ }_{5} \mathrm{O}$ cronista Diego de Valera (1412-1488) é uma importante fonte de consulta sobre os reinados dos últimos trastâmaras. Era filho do médico do rei Juan II e, embora fosse cristão novo, foi membro das Cortes de Henrique IV e Conselheiro dos Reis Católicos. Para ele, "todo homem, como criatura de Deus, tem o direito de ser ouvido".
} 
obedesce las leyes, siguiendo las virtudes e fuyendo los vícios, es dicho justo legal (VALERA, Exortación de la pas, 1959, p. 80-81).

Para Diego de Valera, portanto, Justiça é dar a cada um o que lhe é devido, caracterizando-se como virtude ética, sendo que para que o homem se considere justo, ele deve ter a disposição permanente de caráter, ou seja, torna-se justo a partir do hábito (VALERA, ExPas , 1959, p. 80).

Semelhante à Aristóteles sobre o assunto Justiça, Valera classificou-a como justiça legal e particular, sendo que, para Valera, o exercício da Justiça também se manifesta no momento de se sancionar, de se estipular penas e castigos visando ao bem da coletividade. No entanto, para a imposição da pena, deve o monarca observar o tipo do delito cometido, a qualificação do delinquente, se houve intenção ou não no momento da prática do ato e se existe a possibilidade de recuperá-lo. Ademais, o tempo e o lugar de onde o delito foi cometido, bem como quem foi o ofendido, seu status social, sua religião, se estrangeiro ou não. No momento de aplicação da pena devem os monarcas, ainda, serem clementes, uma vez que a clemência se caracteriza como uma virtude própria dos príncipes. Por fim, não devem utilizar a aplicação das penas como forma de vingança pessoal, pois não seriam monarcas justos, mas sim tiranos (VALERA, Exortación de la pas, 1959, p. 83).

Conforme Vidotte (2005, p. 74), Valera, resgatando os ensinamentos aristotélico e tomista, concebe a idéia de Justiça como aquilo que se dá a cada um de acordo com o que lhe é devido, surgindo, daí, a questão da igualdade. Já Aristóteles, num primeiro momento, consagra a igualdade numérica quando se dá o que é devido às pessoas pelo número e pelo volume das coisas recebidas.

Justiça é algo que abrange comportamentos do cotidiano, que se referem à moral e à ética, não prejudicando ao próximo seja física ou psicologicamente, e atos que visam reparar injustiças. Nesses parâmetros, seguindo a mesma linha de raciocínio de Aristóteles e de Aquino, assim considera Valera:

Cerca destas cosas es de considerar que en qualquier manera de justicia particular, la egualidad es de guaradar segunt cierta proporción; que si todas las cossas que se deven dar o distribuir se diesen igualmente a todos, no seria justicia distributiva, mas grande injusticia. Mas dévese en ello acatar la qualidad de las personas, la virtudes, linajes, estados, servicios, tienpos; que bien asi como en el cuerpo humano los miembros no son eguales nin igualmente los vestimos, mas a cada uno segunt su proporción, así en el cuerpo misto, que es un reino, provincia o comunidad, se deve proporcionar, dando mayores cossas a los más grandes e más dignos, no dexando por eso de fazer bien a todos según los méritos de cada uno (VALERA, Exortación de la pas, 1959, p. 82). 
O autor coloca certas considerações sobre a prática da justiça por meio da equidade de proporção. As coisas não devem ser distribuídas igualmente a todos de maneira literal, senão fazer-se-ia injustiça, ao invés de não justiça. Portanto, acata-se a singularidade do caso e das pessoas envolvidas nele, podendo se observar que da mesma forma que os membros do corpo humano não são iguais, mas que cada parte resguarda a sua importância, para haver uma justiça que proporciona qualidade distributiva, cabe dar a cada um segundo as virtudes ou os méritos, por exemplo.

Esses critérios de se fazer Justiça não foram observados no reinado de Enrique IV, havendo pontos de conflito entre o Rei e a nobreza, pelo fato de que o monarca, ao distribuir honrarias para os homens da baixa nobreza, cometia grave injustiça com os demais, já que os méritos eram desprezados, tendo sido em Valera a justificativa encontrada pelos nobres para se oporem ao monarca.

Pela polissemia que a prática da Justiça requer, para que fosse aplicada a Justiça com características das classificações aristotélicas reinterpretadas por Aquino, houve a junção de um pensamento que se refere ao conceito de Justiça como hábito virtuoso, visando ao bem comum, dando ao outro o que lhe é devido, na medida de sua igualdade, além de considerar a questão religiosa, caracterizando-se como um caminho que conduziria o homem até Deus, devendo pois a Justiça orientar o homem nos campos temporal e transcendental.

Podemos concluir, pelo exposto que, Valera ${ }^{6}$, ao discutir a questão da Justiça durante o Reinado dos Reis Católicos, valeu-se dos ensinamentos aristotélico-tomista, observando sempre a forte presença da religiosidade. No mesmo sentido, os Reis Católicos, ao aplicarem a Justiça, deveriam ser justos, conduzindo seus súditos a uma vida justa, caminho necessário para se chegar até Deus, pois, para eles:

\section{[...] tenemos continuo pensamiento e queremos con acuciosa obra ejecutar nuestro cargo haciendo y administrando justicia, lo cual, como sea obra e edificio grande, ha menester rega para que vaya derecho e su fin se enderece a Dios. \\ (CORTES DE TOLEDO DE 1480, CORTES DE LEÓN Y CASTILLA, IV, p. 110)}

Durante o reinado dos Reis Católicos, a grande problemática levantada por seus pensadores, Arévalo e Valera, era como efetivar a Justiça e manter a paz para se atingir o

\footnotetext{
6 "E porque Señor, el humano trabajo aprovecha poço si en Dios no es ordenado, a El demandad verdadera pas, d'Él esoerad verdadera concórdia, en El ordenad vuestra voluntad" (VALERA, Exortación de la pas, 1959, p. 78).
} 
intuito do projeto centralizador por tais monarcas proposto. A resposta encontrada foi a elaboração de um sistema jurídico forte, com um Direito visto como agente condutor para a realização da Justiça, buscando-se superar os direitos locais e se implantar um direito de caráter geral.

Ao se considerar que Justiça, Direito e lei são conceitos distintos, sendo a lei aquela que instrumentaliza o Direito, tendo este o objetivo final de se atingir a Justiça, Isidoro de Sevilha ${ }^{7}$, nas Etimologias ${ }^{8}$, faz essa distinção:

1. Derecho es un nombre genérico; 'ley' es un aspecto concreto del derecho. Se llama "derecho" (ius) porque es justo. Todo derecho está integrado por leyes y costumbres. 2. "Ley" es una disposición escrita. 'Costumbre' es una prática avalada por la antigüedad; es decir, viene a ser una ley no escrita. 'Ley' deriva de 'leer', ya que está redactada. 3. Lo costumbre, en cambio, es una práctica de larga tradición y referida únicamente a los usos. Por lo tanto, lo costumbre es una especie de derecho instituido por la práctica y utilizado como ley cuando ésta no existe. Y no importa que una norma tenga su base en la escritura o sólo en la razón, ya que la razón es lo que avala a cualquier ley. 4. Pues bien, si toda ley tiene su fundamento en la razón, será ley todo lo que esté fundado en ella, con tal de que esté de acuerdo con la religión, convenga a la doctrina y aproveche para la salvación. Se llama "costumbre" porque son de uso común (Livro V, 3, p. 1-4).

São Isidoro, nas Etimologias, discorre sobre a definição de lei e a classificação do Direito, fazendo a seguinte divisão: direito público, destinado aos magistrados e sacerdotes; direito quiritário se refere aos cidadãos romanos; direito natural, inerente à razão dos homens e fundado no instinto humano, sendo, portanto, aplicável a todas às nações; direito civil, aquele particular de cada povo, destinado a reger internamente cada sociedade; direito das

\footnotetext{
${ }^{7}$ Isidoro de Sevilha (560-636) pertenceu a uma família católica de origem bizantina ou hispano-romana. Como Bispo de Sevilha, o irmão de Isidoro, Leandro de Sevilha, foi o instrumento decisivo para conseguir a renúncia oficial ao arianismo dentro do reino visigodo, proclamada no III Concílio de Toledo. Isidoro sucedeu a Leandro como bispo por volta de 600 e, durante o seu bispado, Sevilha desfrutou de preeminência como centro intelectual do reino visigodo.

${ }^{8}$ Etimologias é a obra mais famosa de Isidoro de Sevilha (560-636), aproximadamente), um estudioso e teólogo considerado o último dos grandes Padres da Igreja Latina. Seu nome tem origem de um método de ensino que prossegue explicando as origens e o significado de cada palavra relacionada a um tópico. Isidoro de Sevilha se baseou em várias fontes diferentes na sua tentativa de resumir todo o conhecimento antigo e salvá-lo para a posteridade. A fama da obra fez com que ela fosse amplamente copiada e disseminada, e sua popularidade durou mesmo até o Renascimento. Para estudiosos medievais, Etimologias era um inigualável compêndio de informações. Este importante manuscrito em letras minúsculas góticas no estilo da escola de Toledo-Sevilha veio originalmente da catedral de Toledo. Ele inclui notas e equivalentes em árabe de algumas palavras em latim. Várias folhas são feitas de cortes de pergaminho, desenhadas grosseiramente. O manuscrito também contém um mapa do mundo com escrita árabe (em 116v) e figuras geométricas coloridas, com títulos, legendas, iniciais e letras maiúsculas em vermelho e verde (disponível em: $<$ https://www.wdl.org/pt/item/10640/>. Acesso em: jul. $\underline{2016}$

) .
} 
gentes rege as relações de interesse comum a todos os povos, como relações diplomáticas, guerra e paz ${ }^{9}$ e; direito militar regula os assuntos de guerra (NADER, 2000, p. 114-115).

No que se refere à definição da lei, Isidoro de Sevilha destaca seus aspectos éticos, sociológicos, filosóficos e técnicos, ressaltando que a lei deve ser honesta, justa e destinada para o bem comum. Quando cuida da classificação da lei, Santo Isidoro a classifica em leis divinas e humanas ${ }^{10}$, tendo as primeiras seu fundamento de validade na natureza, ao passo que as segundas encontram seu fundamento de validade nos costumes dos homens. As leis humanas têm como finalidade a organização legal do povo, devendo ser sancionada pelos anciões juntamente com a plebe (Etim, V, 10). Ademais, devem as leis ordenar condutas, permitir ou proibir condutas visando ao convívio social, bem como a punição em caso de infração à tais leis. Assim,

Las leyes se dictan para que, por temor a ellas, se reprima la audacia humana; para que la inocencia se sienta protegida en medio de los malvados y para que, entre esos mismos malvados, el miedo al castigo refrene su inclinación a hacer daño (Etim., V, 20).

São Tomás de Aquino, influenciado pelos ideais aristotélico e de Isidoro de Sevilha, classifica a lei como sendo eterna, natural divina e humana, sendo que esta se coloca como sendo o ordenamento da razão visando ao bem comum, promulgado pelo chefe da comunidade (NADER, 2000, p. 123).

Como base nos ensinamentos de Santo Isidoro e Aquino, bem como nos preceitos aristotélicos, Arévalo e Valera constroem suas interpretações sobre leis e Direito a fim de aplicá-las no reinado de Fernando e Isabel. Arévalo, em sua Suma de la política, na mesma linha tomista e isidoriana, define a lei como sendo obra da razão humana, inspirada por Deus, que visa ao bem comum, tendo sido promulgada pelo governante ${ }^{11}$, devendo, ainda, apresentar determinados elementos para que seja considerada justa e legítima.

Assim, as leis devem ser possíveis segundo a natureza, devendo também estar em conformidade com a lei divina. Tais devem ser adequadas aos costumes vigentes, bem como

\footnotetext{
${ }^{9}$ Seria o equivalente ao atual Direito Internacional Público, que pode se conceituar como sendo o ramo de direito que tem como finalidade reger as relações que se dão na sociedade internacional.

${ }_{11}^{10}$ Etimologias, V, 2, 1.

${ }^{11}$ La derecha ley es una admirable invención umana fallada por dono y beneficio divinal, por qual las ciudades son compuestas, ordenadas y regidas y los delictos y excessos son corregidos, la qual manda lo onesto y defiende lo contrario. Pues, el buen político debe ordenar las leyes onestas y corregientes los maleficios. Debe esso mesmo establecer tales leyes que principalmente acaten al bien comu de la ciudad o reino y no a otro particular fin. (Sum Pol, II, X, p. 297).
} 
promulgadas pelo chefe da comunidade, quem seja, o príncipe, contendo os efeitos corretivos, punitivos e premiativos, sendo que as leis antigas devem prevalecer sobre as novas, somente se falando em substituição quando aquela se mostrar danosa.

Ca primeramente deven ser posibles según natura, y no solamente posibles, mas aun conforme a la natura, señaladamente quanto a perpetuar la generación humana. Lo II ${ }^{o}$ : debe la ley ser conforme a la ley divina. Onde dize Sant Agustin ... que la ley umanal tiene una imagen de la ley divinal, la qual dize: por mí reinan los reyes y por mí los establecedores de las leyes fazen justos decretos. Onde concluye, que tanto vigor tienen las leyes umanas en quanto non son contrarias a la ley de Dios.

Lo III ${ }^{\text {: }}$ debe ser la ley conforme a la costumbre de la tierra o reino donde se faze, ca de otra guisa no abría efficacia, e por esto dize Aristótiles, en el quarto de las Políticas, que las policías y regimientos de las ciudades no deven ser adaptadas según las leyes, mas las leyes se deven fazer y adotar según las ciudades y según la natura y diversidad dellas.

Lo III $j^{\circ}$ : debe aver auctoridad de principe en la ordenar y consejo del pueblo, ca de otra guisa no sería efficacia.

Lo $v^{o}$ : debe toda ley aver ciertos effectos. Conviene saber: mandar, permitir, proibir, guarlardonar, punir; y mandar lo justo e bien, proibir lo malo e lo injusto, permitiendo las cosas indiferentes; premiar a los buenos, punnir a los malos ...

Lo vj : debe el rey o todo buen político ser muy solícito en guardar las leyes antigas, y no debe ser prompto para las inorar por leyes nuevas, salvo quando mucho conviene o si las primeras leyes son dañosas (SumPol, II, X, p. 298)

Deste modo, assim como ocorre no se pensar a Justiça durante o reinado dos Reis Católicos, o mesmo ocorre com a questão do Direito e da lei. Como acontece com a questão da Justiça, do Direito e da lei, tanto na sua produção quanto aplicação devem ir ao encontro aos preceitos religiosos, sendo que lei e Direito devem estar baseados na lei natural, que está baseada na lei divina. Deve, ainda, de acordo com os ensinamentos de Arévalo, a lei ter sido promulgada pelo governante, visando ao bem comum. Ademais, referida lei deve ter sido ordenação da razão sob inspiração divina.

Com base nesta análise teórica sobre os conceitos de Direito e Justiça, passemos ao estudo do ordenamento jurídico vigente à época dos Reis Católicos, qual seja, as Ordenanzas Reales de Castilla.

\section{DO LIVRO II DAS ORDENANZAS REALES DE CASTILLA: O DIREITO ENQUANTO FIO CONDUTOR PARA A CONSECUÇÃO DA JUSTIÇA.}

As Ordenanzas Reales se originam nas Cortes de Toledo de 1480, ocasião em que os Reis Católicos encarregam o jurista Alonso Díez de Montalvo de elaborar um ordenamento jurídico capaz sistematizado. Tal texto disciplina, dentre outros assuntos, a atuação dos 
monarcas na elaboração, aplicação e administração da Justiça, a disposição espacial e a forma como os Reis deveriam se deslocar para atingir tal objetivo, bem como as cerimônias.

Durante o reinado dos Reis Católicos, duas grandes obras jurídicas foram promulgadas, na esfera do direito público e do privado: as Ordenanzas Reales de Castilla e o Libro de las Bulas y Pragmáticas (1973). Este livro se caracterizava como normas jurídicas de direito público de caráter geral, aplicando-se, assim, a todos indistintamente. Aquelas, elaboradas por Montalvo, abordam sobre diversas matérias jurídicas, configurando-se, pois, como uma compilação de leis, tendo tido como base As Siete Partidas, de Afonso o Sábio; estas, por sua vez, compõe-se por meio da emissão de pragmáticas, cédulas, provisões e demais disposições às quais se uniriam algumas ordenações e reis anteriores e outras bulas papais, incluindo as Leyes de Toro, assim denominadas por terem sido promulgadas na cidade de Toro no ano de 1505, que disciplina relações de direito privado, destacando-se, dentre outras, normas aquelas relativas ao direito matrimonial, filiação, capacidade da mulher e direito sucessório.

Ao se inspirar em todas essas bases para a sua elaboração, as Ordenanzas Reales de Castilla reúne 1163 leis agrupadas por matérias divididas em 15 títulos e 8 livros, sendo que o Livro II é dividido em 23 títulos e 291 leis relativas à jurisdição régia e direito público em geral.

Interessante obervar que de todos os livros que compõem as Ordenanzas Reales de Castilla o que mais se aproxima de nosso objeto de pesquisa é o Livro II por ser ele o que, de forma sistemática, disciplina sobre a aplicação e distribuição da Justiça. O Título I, composto por 07 leis, nos traz as regras sobre Como debe el Rey oir y librar, pois, neste Título, temos os momentos em que eram permitidos aos reis julgarem, sendo que Valera entendia que competia aos Reis a aplicação da Justiça distributiva, sendo seu posicionamento minoritário.

De acordo com as Ordenanzas Reales ${ }^{12}$,

El Rey funda su intención de derecho común acerca de la jurisdicción civil, y criminal en todas las Ciudades, Villas, y Lugares de sus Reynos, y señorios. Y por esto antigamente ordenaron los Reyes nuestros progenitores, y nos ordenamos, que cualquier Perlado, hombre poderoso, que tiene entrada, y occupada la jurisdicción (b) de cualquier de las dichas Cidades, y Villas, y Lugares, es tenudo de mostrar, y muestre ante nos titulo, ó privilegio por donde la tal jurisdicción le pertenezca; en otra manera no sería consentido usar delle (ORC, II, I, IV).

12 “Que los que usan de jurisdicion en la tierra del Rey, muestren el titulo o privilegio" (ORC, II, I, IV). 
Para a aplicação da Justiça, observe-se a relação de temor a Deus e amor à Justiça, competindo aos Reis, por meio da aplicação da Justiça, proporcionar o bem-estar coletivo.

Para a aplicação e administração da Justiça, os Reis Católicos deslocavam-se por todo o reino, imprimindo um caráter itinerante para seu governo, tendo eles observado à risca as decisões tomadas nas Cortes de Toledo de 1480. De acordo com a Ley III, Titulo I, Libro II: "que il rrey ande por toda la tierra a administrar a justicia",

Para o exercício da função de aplicar e de administrar a Justiça, tendo sempre em mente o pensamento então vigente, os Reis deveriam ser investidos nessa atuação que lhes fora conferida por Deus, corrigir, punir e castigar. No entanto, ao exercer essa função aplicação da Justiça, os reis deveriam ser extremamente cautelosos, uma vez que é muito tênue a linha que separa a Justiça da injustiça ou da crueldade. Para Pulgar, em sua obra Crônicas aos Reis Católicos (1943, p. 313):

El rigor de la justicia engendra miedo, y el medo turbación, y la turbación algunas
veces desesperaçión e pecado; y la piedade proced. amor, y del amor caridad, y de
la caridad siempre se sigue mérito y gloria. [...]la Sacra Scriptura está llena de
loores ensalçando la piedad, la mansedunbre, la misericórdia e clemência, que son
títulos e nombres de Nuestro Señor [...] E por el contino uso de su clemência Le
llamamos: "miserator, misericors, paçiens, multi misericorida". Mire bien Vostra
Alteza quantas vezes refiere este su nombre de misericordioso, lo que fallamos veces
tan repetidas del nombre de justiçiero, e mucho menos de reguroso en la justicia.

Deste modo, em certos momentos, os monarcas agiam de forma misericordiosa ora de forma rígida. No entanto, em ambos os casos, sempre agindo com Justiça. Neste ponto, retomamos aos ensinamentos aristotélicos no sentido de que a virtude se encontra no meiotermo. Conforme as situações apresentadas, os monarcas alternavam a aplicação da Justiça com atos de misericórdia e com atos rígidos. Deveriam se colocar como misericordiosos, sem, todavia, deixarem transparecer a imagem de fracos. Por esse motivo adotavam uma prática interessante: ao serem rígidos, alimentavam o temor de seus súditos em relação a eles, ao estabelecerem o dia do perdão, concediam perdão a uma coletividade, demonstrando a face de misericordiosa dos Reis.

Em relação à produção do Direito, No momento de elaboração das leis, os monarcas deveriam estar atentos aos conceitos de leis e de Justiça, mas, sobretudo, observar a obediência, no processo legislativo, aos preceitos divinos. A lei era vista como obra da razão humana, mas baseada nos preceitos divinos, visando ao bem-estar da comunidade como um todo. A concepção utilizada pelos Reis Católicos visava à manutenção da paz pela aplicação 
de uma lei justa, estimulando os bons a buscarem por uma vida virtuosa e punindo os maus pelos atos injustos praticados.

Neste contexto, a elaboração e promulgação das leis sob a égide dos preceitos divinos legitimava a sua Justiça para conduzir as ações de seus súditos, pelos preceitos legais do bem comum, estimulando-os a ter uma vida virtuosa, mas se necessário punindo e castigando aos que não obedecem às leis. ${ }^{13}$ Assim, considerados como bons políticos,

Pues, el buen político debe ordenar las leyes honestas y corregientes los maleficios. Debe esso mesmo establecer tales leyes que principalmente acaten al bien comúm de la ciudad o reyno y no a otro particular fin. Onde dize Aristótiles que no hay persona alguna que discreta sea, que ordene y faga leyes por causa dellas mesmas, mas por salvar y conservar la república, ca la ley es como melezina al cuerpo humano, a qual fue instituida para sanar al cuerpo y no a otro fin. E assí la ley no se debe ordenar, salvo quanto aprovecha al bien común de la ciudad o reyno por cuya causa es fecha, y no por otros particulares provechos (ARÉVALO, 1959, II, X).

A possibilidade de os monarcas legislarem, entendida aqui em sentido amplo como o de criar e modificar normas jurídicas, mostra-se presente nos corpos jurídicos da época - Ordenanzas Reales de Castilla (I, IV) e Leyes de Toro de 1505. De acordo com a Ley I, das Cortes de Toro (1505): "E porque al rey pertenesce e a poder de facer fueros e leyes y de las interpretar e declarar e emendar donde viere que cumple".

No entanto, ao legislar, os monarcas deveriam, ainda, observar os costumes locais pois, nesse contexto histórico, o Direito era visto como emanado da própria sociedade. Desta forma, os monarcas criavam as leis, respeitando os costumes, adaptar o direito antigo aos tempos atuais. Assim o costume, enquanto fonte do Direito, continuava vigorando, ainda que não totalmente positivado.

Para Gurevith (1990, p. 206), embora a produção do Direito possuísse espírito inovador a sua prática era conservadora. Nesta perspectiva, as leis promulgadas deveriam ser aplicadas em todo o reino, respeitando, todavia, os costumes locais ${ }^{14}$. Neste ponto, o rei, ao julgar, estaria atento às realidades daquela localidade, bem como à diversidade de estados ${ }^{15}$.

\footnotetext{
${ }^{13}$ Neste mesmo sentido, Álvaro Pelayo, citado por Villapalos Salas (1997, p. 51): “estimular a sus súbditos en una vida de virtud".

${ }^{14}$ Para Arévalo (Sum. Pol, II, X): “Debe otrosí la ley ser común para todas las personas, y que ligue y constriña así a los ricos como a pobres, assí a poderosos como a flacos; e no sea así como la tela de la araña, la qual sostiene a los animales flacos, pero a los fuertes non se estiende".

${ }^{15}$ Valera nos informa, em sua Exortación de la Pas (p. 82), que: "Ca en una manera nos devemos aver con el plebeo, en otra con el noble; en otra con el siervo, en otra con el libre; en otra con el viejo, en otra con el mancebo; en otra con el pobre, en otra con el rico; en otra con el que muchas vezes yerre, en otra con el que una vez erró; en otra con el que yerra acaso, en otra con el que con voluntad deliberada de yerrar; en otra con el que costreñido por necesidad, en otra con el que de grado; en otra con los incorregibles, en otra con los de quien se espera corrección; en otras con los parientes, en otra con los estraños; en otras con los naturales, en
} 
Ademais, haveria a preocupação no momento de interpretação das leis, ou seja, elas deveriam ser compreendidas por todos do reino, pois só assim seriam respeitadas e cumpridas. Por isso, tais leis seriam devidamente publicadas e, para que fossem legítimas, elaboradas pelo monarca.

A atividade legislativa dos monarcas era abrangente, mas não ilimitada, caracterizando-se, pois, como competência exclusiva, a qual, deste modo, não poderia ser delegada. Além disto, os Reis Católicos não legislavam a todo o momento, pois somente legislariam caso fosse verdadeiramente necessário, uma vez que se esperava que as leis antigas resolvessem os conflitos que surgissem.

Arévalo, retomando os ensinamentos aristotélico, os Reis legislavam embasados nos costumes, porque a mudança das bases legais significava coisa perigosa para todos. Quando uma lei é instituída, requer um tempo para que os cidadãos se acostumem com a ela, ganhando mais eficácia tão logo as pessoas habituem suas ações para respeitá-la.

A despeito de tal perspectiva - legislar em casos verdadeiramente necessários e criando leis para promoção da Justiça - o que se percebe é a intensa atividade legislativa de Fernando e Isabel, usando os costumes do povo. De acordo com Vidotte (2005, p. 112), a produção legislativa era tão intensa - e, em alguns casos, impensadas, sobretudo pelas bulas pragmáticas e provisões, que acabou gerando diversos problemas, como a promulgação de leis ora contraditórias entre si, ora com os costumes de certos locais, provocando confusões e insatisfações ${ }^{16}$.

Para contornar tal situação, aplicou-se o princípio do "que se obedeça mas que não se cumpra", ou seja, embora a lei tenha sido promulgada pelo poder competente e possuísse vigência, não era eficaz. Embora em alguns momentos a intensa produção legislativa tenha causado problemas aos monarcas, essa se justificou pela necessidade inerente ao período analisado.

otra con los estrangeros; en otra con los catolicos, en otra con los infieles; en otra con los que ofenden la majestad real, en otra con los que ofenden el pueblo; en otra con la muchedunbre que yerra".

16 Nesse sentido, Valera alertava Fernando e Isabel sobre os inconvenientes de se promulgarem tantas leis, algumas vezes, contraditórias. Aconselhava, assim: "Vuestra Altesa debe remediar en una cosa que mucho toca vuestro honor e servicio, la qual es, que mande que las cartas que de vuestro Consejo se dieren, o por espediente o merced Vuestra Señoria mandare dar, se den así justas que no convenga revocarlas; porque en algunas vuestras ciudades he visto desto mucho murmurar diziendo Vuestra Altesa aver enviado cartas contrarias unas de otras, lo qual no conviene a los reyes faser sin grandes e justas cabsas" (TrEp, Epístola IX, p. 15). 
O Direito era visto como forma de afirmação dos monarcas, os quais visavam instituir um direito geral, o qual deveria se sobrepor aos direitos locais, sempre. Entretanto, respeitando a tradição, foi por meio de tal atitude: legislar e julgar, que houve a promulgação de um ordenamento jurídico forte, baseado no conceito de Justiça. Assim, Fernando e Isabel realizaram uma profunda reforma política, levando à unificação e, conseqüentemente, ao fortalecimento do reino ${ }^{17}$.

\section{CONSIDERAÇÕES FINAIS}

A presente pesquisa situou-se, cronologicamente, entre os anos de 1474 a 1504 e, geograficamente, no reino ibérico de Castela. Teve como principal objeto o ordenamento jurídico vigente à época dos Reis Católicos e a forma como estes monarcas aplicavam e distribuíam a Justiça a fim de que se desse a centralização do poder político e da função legislativa e julgadora em suas mãos. Nesse período histórico - final da Idade Média e início da Idade Moderna - apresenta-se como sendo o momento de consolidação das monarquias europeias e, consequente, surgimento do Estado moderno. Nesse contexto histórico também ocorre a centralização da função legislativa nas mãos do monarca que agora, além de agir como julgador, também age como legislador.

A Espanha, com suas peculiaridades, também caminhou para a centralização política durante esse período, sobretudo, após a união de Isabel de Castela e Fernando de Aragão, os quais puderam transmitir a um único herdeiro os reinos de Castela e Leão, Aragão, Navarra e Granada, portanto os reinos ibéricos exceto Portugal. Dada a importância de tais reis para a consolidação da monarquia espanhola, tais monarcas foram, por séculos, vistos como os forjadores do Estado espanhol moderno. No entanto, a partir das fontes do período, bem como da leitura de autores medievais e contemporâneos, pudemos perceber que Isabel e Fernando, ao reestruturarem os institutos existentes e reformular o ordenamento jurídico vigente para que houvesse a aplicação e distribuição da Justiça, tornaram possível essa centralização política. Entendemos que foi sobretudo com a reformulação do ordenamento jurídico, a partir de agora de caráter geral e promulgado pelos monarcas - muito diferente do

\footnotetext{
${ }^{17}$ De acordo com Villapalos Salas (1997, p. 55): "El absoluto predominio del Derecho escrito y la aspiracón de los Reyes Católicos a unificar la legislación aportaría pronto sus primeros frutos: el Ordenamiento de Montalvo, u Ordenanzas Reales de Castilla, y en paralela medida, o mayor, si considerarmos su pleno carácter oficial, el Libro de las Bulas y Pragmáticas".
} 
antigo direito consuetudinário e local - e com a aplicação e distribuição da Justiça - que se incrementa com a reestruturação das instituições existentes - que se caminha para a consolidação da monarquia espanhola e centralização política.

O ordenamento passa a ter caráter geral, tendo suas leis promulgadas pelos monarcas - muito diferente do antigo direito consuetudinário e local - e com a aplicação e distribuição da Justiça. O reinado dos Reis Católicos se configurou como etapa decisiva para o processo de consolidação e de centralização do poder reinante.

Para sua validade e obrigatoriedade, as leis deveriam ter sido promulgadas pelo governante que o fazia com base na razão, mas sob inspiração divina. A partir dessa análise, o estudo das Ordenanzas Reales de Castilla passa ser a base crucial para a pesquisa, em específico seu Livro II, o qual trata de como os reis podem julgar e disciplinar a composição e o funcionamento dos órgãos responsáveis pela aplicação e distribuição da Justiça. As Ordenanzas Reales de Castilla foram elaboradas pelo jurista Alonso Diaz de Montalvo, após convocatória feita nas Cortes de Toledo de 1480 que foram de extrema importância para o desenvolvimento da presente tese, uma vez que nelas se reforça o poder real.

Pelo estudo das fontes, foi possível verificar o modo de produção e aplicação do Direito e da Justiça, a organização e funcionamento do Conselho Real, Audiência e Chancelaria, bem como a atuação do Rei enquanto juiz. Já para se verificar a atuação do monarca enquanto legislador a fonte analisada foi o Especulo. Também se verificou que, ao mesmo tempo em que os reis especializavam cada vez mais as instituições vigentes, mantiveram participação efetiva em suas atividades. A organização espacial de cada órgão e o modo como seus membros deveriam atuar eram bem arquitetados politicamente para a sua efetivação.

Após a análise das fontes (textos legislativos e crônicas do período), bem como de estudos realizados ao longo dos séculos sobre o reinado de Isabel e Fernando, conclui-se que o conceito de Justiça, polissêmico e dinâmico, à época dos Reis Católicos, fundamentava-se na concepção aristotélico-tomista, assim como o conceito de Direito. Deste modo, os monarcas, ao legislarem ou julgarem, deveriam ser justos, tendo como objetivo principal a condução de seus súditos ao bem-comum. Essa questão ficou mais aguçada na leitura das crônicas de Pulgar (Crônicas dos Reis Católicos), nas quais são relatadas passagens em que os Reis administram e aplicam a Justiça. Muitas vezes, para serem ainda mais justos, julgavam em sentido contrário ao que se encontrava posto nas leis vigentes. 
Assim, os monarcas estavam preocupados em serem justos, em não ferirem os preceitos divinos, em aplicarem e distribuírem a Justiça de forma exemplar. Para fins de consolidação da monarquia e centralização política, houve a reforma das instituições e a reformulação do próprio corpo jurídico. Deste modo, por meio da aplicação e distribuição da Justiça e da reestruturação das instituições, Isabel e Fernando atingiram seu objetivo, qual seja, o fortalecimento da monarquia e a centralização política.

\section{FONTES HISTÓRICAS E REFERÊNCIAS BIBLIOGRÁFICAS}

\section{FONTES HISTÓRICAS:}

AFONSO X, o Sábio. Las siete partidas. Madrid: Boletim oficial del Estado, 1985. 3v. Ed. Fascimil da versão glosada por el Licenciado Gregório Lopez. Salamanca, 1516.

Allegações de D. Afonso de Cartagena, Bispo de Burgos (ao Concílio de Basiléia), por parte do Rei de Castela, contra a conquista das Ilhas Canárias pelos portugueses e favor da conquista das mesmas Ilhas pelo dito Rei. Tradução portuguesa, anotada, do Dr. Jose Saraiva. [Allegationes factas per reuerendum patrem dominiun alfonsum de cartaiena Episcopum burgensem in consilio bassilensi super conquesta Jnsularum Canarie Contra Portugalensses Anno domini M. CCCC. Tricessimo $5^{\circ}$. In: Descobrimentos portugueses. Documentos publicados e prefaciados por João Martins da SILVA MARQUES. V. 1, págs. 321-346 [págs. 295-320].

ARÉVALO, R. Suma de la Politica. In: Prosistas castellanos del siglo XV. v. 1. Ed. de Mario Penna. Madrid: Atlas, 1959, p. 249-309 (Biblioteca de Autores Españoles, 116).

ARISTOTELES. Ética a Nicômaco. Vol. 2. Trad. Pietro Nassetti. Coleção Os Pensadores. São Paulo: Nova Cultural, 1991.

DIOS, Salustiano (ed.). Fuentes para el estudio del Consejo Real de Castilla. Serie Fuentes, 1. Salamanca: Ediciones de la Diputación de Salamanca, 1986.

MAQUIAVEL. $O$ Príncipe. Ed. Ridendo Castigat Moraes. Versão para Ebook ebooksbrasil.com. Fonte digital www.jahr.org. 2000

Ordenanzas Reales de Castilla - Copilacación de leyes del reino, de Afonso Díez de Montalvo, realizada en el año 1484. Ed. Fac-símile da primeira edição de 1484. Valladolid: Lex Nova, s/d, exemplar 97/1.600.

PULGAR, Fernando del. Crónica de los Reyes Católicos. 2v. ed. Juan de Mata Carriazo. Madrid: Espasa-Calpe, 1943 (Colección de Crónicas Españolas, V-VI).

TOMÁS DE AQUINO. La Leye. Versión castellana y notas explicativas de Constantino Fernández Alvar. Barcelona: Labor, 1936.

VALERA, Mosen Diego. Exortación de la pas. In: BAE, 116: Prosistas castellanos del siglo XV, v.I, Ed. de Mario Penna, BAE, Madrid: Atlas, 1959, p. $77-87$ (Biblioteca de Autores Españoles, 116).

\section{REFERÊNCIAS BIBLIOGRÁFICAS}

ABBAGNANO, Nicola. Dicionário de filosofia. $4^{\mathrm{a}}$ ed. São Paulo: Martins Fontes, 2000.

ABBAGNANO, Nicola. História da Filosofia. Volume I. $5^{a}$ edição. Tradução de António 
Borges Coelho, Franco de Sousa e Manuel Patrício. Lisboa: Editorial Presença, 1991.

ALMEIDA, Néri de Barros \& SILVA, Marcelo Cândido da. (org.). Poder e construção social na Idade Média: história e historiografia. Goiânia: Ed. UFG, 2012.

BECEIRO PITA, I. y CORDOBA DE LA LLAVE, R. Parentesco, poder y mentalidad. La nobleza castellana - siglos XII-XV. Madrid: CSIC, 1990.

BITTAR, E. C. B. Teorias sobre justiça. São Paulo: Editora Juarez de Oliveira, 2000.

BITTAR, E. C. B. A justiça em Aristóteles. 3. Ed. Rio de Janeiro: Forense Universitária, 2005.

BITTAR, E. C. B. Curso de filosofia aristotélica: leitura e interpretação

do pensamento aristotélico. Barueri, SP: Manole, 2003.

CHARTIER, R. A história cultural. Entre práticas e representações. Rio de Janeiro: Difel, 1990.

DEL VECCHIO, G. Lições de filosofia do direito. 5.ed. Coimbra: Armênio Amado Editor, 1979

ELIAS, N. O processo civilizador. 2v. Rio de Janeiro: Jorge Zahar, 1990.

GOYARD-FABRE, S. Os princípios filosóficos do direito político moderno. São Paulo: Martins Fontes, 1999.

GROSSI, P. Mitologias jurídicas da modernidade. Florianópolis: Fundação Boiteux: 2004.

GROSSI, P. El orden jurídico medieval. Madrid: Marcial Pons, 1996.

KANTOROWICZ, E. H. Los dos cuerpos del rey. Madrid: Alianza, 1985.

LADERO QUESADA, M. A. La España de los Reyes Católicos. Madrid: Alianza, 1999.

LE GOFF, J. Para um novo conceito de Idade Média. Lisboa: Estampa, 1980.

LOPES, J. R. L. O direito na história: lições introdutórias. São Paulo: Max Limonad, 2000.

LOPES, M. A. A imagem da realeza. Simbolismo monárquico no Antigo Regime. São Paulo:

Ática, 1995.

MARAVALL, J. A. El concepto de España en la Edad Media. Madrid: Centro de Estudios Constitucionales, 4. ed., 1997.

MARONGIU, A. Un momento típico en la monarquia medieval. El rey-juez. In: Anuario de Historia del Derecho Español, XXIII, 1953, p.677-715.

MARTÍN, J. L. Las cortes medievales. Madrid: Historia 16, s/d.

MENENDEZ PIDAL, R. Los Reyes Católicos y otros estudios. Buenos Aires: Espasa-Calpe, 1962.

NADER, P. Filosofia do direito. Rio de Janeiro: Forense, 2000.

NIETO SORIA, J. M. Legislar y gobernar en la Corona de Castilla: el Ordenamiento Real de Medina del Campo de 1433. Madrid: Dykinson, 2000.

NIETO SORIA, J. M. (dir) Orígenes de la monarquia hispánica. Madrid: Dykinson, 1999.

NIETO SORIA, J. M. La transpersonalización del poder regio en la Castilla bajomedieval. Anuario de Estudios medievales, 17, 1987, p.559-570.

PEREZ, J. Isabel y Fernando. Los Reyes Católicos. Madrid: Nerea, 1988.

PEREZ, J. Los Reyes Católicos ante los movimientos antiseñoriales. Violencia $y$ conflictividad en la sociedad de la España Bajomedieval. IV Seminario de Historia Medieval.

Zaragoza: Universidad de Zaragoza, 1995, p.91-99.

PEREZ-BUSTAMANTE, R. Historia del Derecho español. Las fuentes del derecho. Madrid:

Dykinson, 1997.

PEREZ BUSTAMANTE, R. y CALDERON ORTEGA, J. M. Enrique IV - 1454-1479.

Burgos: La Olmeda, 1998. (Corona de España, XI)

REALE, M. Filosofia do Direito. 20 ed. São Paulo: Saraiva, 2002

RUCQUOI, A. História medieval da Península Ibérica. Lisboa: Estampa, 1995. 
RUIZ, T. Sociedad y poder real en Castilla. Madrid: Ariel, 1981.

SALUSTIANO DE DIOS. El Estado Moderno, ¿un cadáver historiográfico? In: RUCQUOI, A. (org.) Realidad e imagenes del poder. Valladolid: Ambito, 1988.

SUÁREZ FERNÁNDEZ, L. Los Trastámaras y Los Reyes Católicos. Madrid: Gredos, 1985. (Historia de España, 7)

SUÁREZ FERNÁNDEZ, L. Nobleza y monarquía. Puntos de vista sobre la história política castellana del siglo XV. Madrid: Rialp, 1989a

SUÁREZ FERNÁNDEZ, L. Los Reyes Católicos. Fundamentos de la monarquia. Madrid: Rialp, 1989b.

SUÁREZ FERNÁNDEZ, L. Los Reyes Católicos: La conquista del Trono. V. 1. Madrid: Ripal, 1989.

TATE, R. B. Ensaios sobre la historiografia peninsular del siglo XV. Madrid: Gredos, 1970.

TENENTI, A. Los fundamentos del mundo moderno. Madrid: Siglo XXI, 1972.

VIDOTTE, A. A historiografia espanhola sobre o reinado dos Reis Católicos. Disponível em: http://www.anpuhsp.org.br/downloads/CD\%20XVIII/pdf/ST\%2013/Adriana\%20Vidotte. pdf. Acesso em 05/10/2011.

VILLAPALOS SALAS, G. Justicia y monarquia. Madrid: Marcial Pons, 1997.

VILLAPALOS SALAS, G. Los recursos contra los actos de gobierno en la Baja Edad Media. Su evolución histórica en el reino castellano. 1252-1504. Madrid, 1976. 